TITLE:

\title{
Total Synthesis of Ellagitannins through Regioselective Sequential Functionalization of Unprotected Glucose.
}

\section{AUTHOR(S):}

Takeuchi, Hironori; Mishiro, Kenji; Ueda, Yoshihiro; Fujimori, Yusuke; Furuta, Takumi; Kawabata, Takeo

\section{CITATION:}

Takeuchi, Hironori ... [et al]. Total Synthesis of Ellagitannins through Regioselective Sequential Functionalization of Unprotected Glucose.. Angewandte Chemie 2015, 54(21): 6177-6180

\section{ISSUE DATE:}

2015-05-18

URL:

http://hdl.handle.net/2433/202533

\section{RIGHT:}

This is the peer reviewed version of the following article:Takeuchi, H., Mishiro, K., Ueda, Y., Fuijmori, Y., Furuta, T. and Kawabata, T. (2015), Total Synthesis of Ellagitannins through Regioselective Sequential Functionalization of Unprotected Glucose. Angew. Chem. Int. Ed., 54: 6177-6180, which has been published in final form at http://dx.doi.org/10.1002/anie.201500700. This article may be used for non-commercial purposes in accordance with Wiley Terms and Conditions for Self-Archiving.: The full-text file will be made open to the public on 9 APR 2016 in accordance with publisher's 'Terms and Conditions for Self-Archiving', この論文は出版社版でありません。引用の際に は出版社版をご確認ざ利用ください。; This is not the published version. Please cite only the published version. 


\title{
Total synthesis of ellagitannins via regioselective sequential functionalization of unprotected glucose
}

\author{
Hironori Takeuchi, Kenji Mishiro, Yoshihiro Ueda, Yusuke Fujimori, Takumi Furuta and Takeo \\ Kawabata*
}

This paper is dedicated to Professor Emeritus Kaoru Fuji for the celebration of his $77^{\text {th }}$ birthday (Kiju).

\begin{abstract}
Short-step total syntheses of natural glycosides (ellagitannins) have been performed by sequential and regioselective functionalization of hydroxy groups of unprotected glucose. The key reactions are $\beta$ selective glycosidation of a gallic acid derivative using unprotected glucose as a glycosyl donor and catalyst-controlled regioselective introduction of a galloyl group into the inherently less reactive hydroxy group of the glucoside.
\end{abstract}

Natural glycosides have been known to exhibit a wide range of biological activities. Due to their pharmaceutical potentials, considerable efforts have been devoted to their synthesis. ${ }^{[1-4]}$ However, synthesis of carbohydrates including glycosides always associates with difficulties in selective manipulation of multiple hydroxy groups, and has been achieved by multi-step protection/deprotection procedures. Here, we describe an extremely short-step total synthesis of ellagitannins by eliminating the use of protective groups for glucose. disclosure of the attractive biological activities of this class of natural glycosides engendered a renaissance of the interest in their chemical synthesis. ${ }^{[1-4]}$ Among the ellagitannins, we chose strictinin (1) ${ }^{[6]}$ and tellimagrandin II (2) (eugeniin) ${ }^{[7]}$ as synthetic targets (Figure 1), which show anti-HSV, ${ }^{[8]}$ anti-tumor, ${ }^{[9]}$ antiinfluenza virus, ${ }^{[10]}$ anti-allergic activities. ${ }^{[11]}$ Their structures basically consist of a central sugar core, typically glucose (Dglucose), to which are esterified gallic acid "galloyl" and hexahydroxy diphenoic acid "HHDP".

Retrosynthetic analyses of strictinin (1) are shown in Scheme 1. A rational retrosynthetic analysis should lead to suitably protected precursor 3 , possessing free $\mathrm{C}(4)-\mathrm{OH}$ and $\mathrm{C}(6)-\mathrm{OH}$ and $\mathrm{C}(1)-\mathrm{X}$ (X: activating group for glycosidation), $\mathrm{C}(2)-\mathrm{OP}$ (P: protective group), and C(3)-OP to introduce an HHDP group at $\mathrm{C}(4)-\mathrm{O}$ and $\mathrm{C}(6)-\mathrm{O}$ of the glucopyranose skeleton. Pioneering studies on the total synthesis of strictinin (1) via precursors depicted as $\mathbf{3}$ have been reported by Khanbabaee and coworkers, ${ }^{[12]}$ and also by Yamada and co-workers. ${ }^{[13]}$

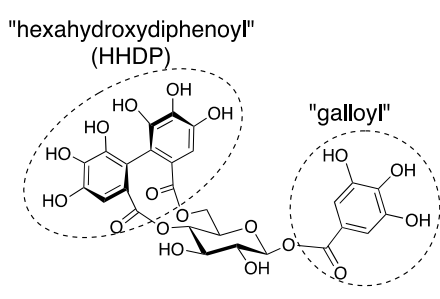

strictinin (1)

Figure 1. Target ellagitannins.

Ellagitannins are a large class of plant polyphenols with a wide variety of biological activities such as antitumor and antiviral activities, and specific polyphenol-protein interactions. ${ }^{[1,2]}$ While ellagitannins have been known for a long time, ${ }^{[5]}$ recent

[a] H. Takeuchi, Dr. K. Mishiro, Dr. Y. Ueda, Y. Fujimori, Dr. T. Furuta and Prof. Dr. T. Kawabata

Institute for Chemical Research, Kyoto University

Uji, Kyoto 611-0011 (Japan)

E-mail: kawabata@scl.kyoto-u.ac.jp

[b] We thank Professor Hidetoshi Yamada, Kwansei Gakuin University, for the valuable suggestions about oxidative phenol coupling. This work was financially supported by a Grant-in-Aid for Scientific Research on Innovative Areas "Advanced Molecular Transformations by Organocatalysts" and a Grant-in-Aid for Scientific Research (S) from MEXT. H.T. acknowledges the financia support through JSPS Research Fellowships for Young Scientists.

Supporting information for this article is given via a link at the end of the document.((Please delete this text if not appropriate)) 
group at $\mathrm{C}(1)$, introduction of the second and third galloyl groups in the order $\mathrm{C}(4)-\mathrm{OH}$ and then $\mathrm{C}(6)-\mathrm{OH}$ was expected to be critical to obtain 1,4,6-trigallate 4 , because once the second galloyl group was introduced at $\mathrm{C}(4)-\mathrm{OH}$, the third one was assumed to be readily introduced at $\mathrm{C}(6)-\mathrm{OH}$ based on the inherent higher reactivity of the $\mathrm{C}(6)-\mathrm{OH}$ among the remaining three free $\mathrm{OHs}$ at $\mathrm{C}(2), \mathrm{C}(3)$, and $\mathrm{C}(6)$. On the other hand, if the second galloyl group was introduced at $\mathrm{C}(6)-\mathrm{OH}$, the third one was expected to be introduced selectively at $\mathrm{C}(3)-\mathrm{OH}^{[14]}$ or in a non-selective manner. Total synthesis of tellimagrandin II (2) was also planned via the regioselective and sequential introduction of five galloyl(oxy) groups to unprotected glucose. If this strategy could be realized, we should be able to eliminate several steps that would otherwise be required for the introduction and removal of the protective groups for glucose. Thus, the synthetic strategy proposed here is expected to provide a revolutionary route to the synthesis of natural glycosides, considering that the only reliable approach to date for the synthesis of glycosides has included the use of suitably protected intermediates such as $\mathbf{3}$.

The first problem is the stereoselective glycosidation of unprotected glucose (Scheme 2). While protected glucose derivatives have generally been used as glycosyl donors for glycosidation, ${ }^{[1-4,15]}$ the methods for glycosidation of acidic nucleophile with unprotected glucose have been reported. ${ }^{[16,17]}$ Shoda and co-workers reported the glycosidation of phenol derivatives with unprotected glucose under Mitsunobu conditions. $^{[16]}$ While the reaction took place regioselectively at the anomeric carbon, it gave an $\alpha / \beta$ mixture of the glycosides. Aime and co-workers also reported that an $\alpha / \beta \square$ mixture $(\alpha / \beta=41 / 59)$ of glycosides was obtained by the treatment of carboxylic acid with unprotected glucose under Mitsunobu conditions. ${ }^{[17]}$ We examined the glycosidation of gallic acid trimethoxymethyl ether (5) using unprotected glucose as a glycosyl donor. After a thorough screening of the conditions (see Supporting Information), we found a highly stereoselective glycosidation. Treatment of a suspension of glucose $(0.03 \mathrm{M})$ and 5 in 1,4-dioxane with diisopropyl azodicarboxylate (DIAD) and $\mathrm{PPh}_{3}$ at room temperature for 30 min gave desired 6 in high stereoselectivity $(\beta / \alpha=99 / 1)$ and $78 \%$ yield. The use of finely ground glucose powder and ultrasound irradiation of the powder suspension in 1,4-dioxane prior to the addition of the Mitsunobu reagents were found to be crucial for the smooth progression of the glycosylation. Although glucose did not dissolve initially in 1,4-dioxane, it did dissolve gradually, and the reaction proceeded within 30 min to give 6 stereoselectively.

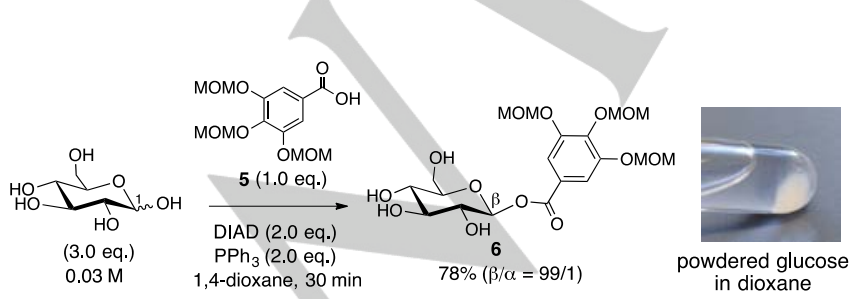

Scheme 2. Direct stereoselective glycosidation.
With $\beta$-glycoside 6 in hand, we next investigated the regioselective introduction of a galloyl group to $\mathrm{C}(4)-\mathrm{OH}$ of 6 (Table 1). We previously developed catalyst $\mathbf{1 1}$, which enabled highly regioselective acylation of octyl $\beta-D$-glucopyranose. ${ }^{[18,19]}$ The catalytic regioselective introduction of a galloyl group with electron-withdrawing acetoxy groups to $\mathrm{C}(4)-\mathrm{OH}$ of octyl $\beta-\mathrm{D}$ glucopyranose was also achieved. ${ }^{[20]}$ Treatment of $\mathbf{6}$ with anhydride $\mathbf{7}$ in the presence of catalyst $\mathbf{1 1}$ under the previously optimized conditions, ${ }^{[20]}$ however, gave the desired 1,4-digallate 9 in only $18 \%$ yield even after $72 \mathrm{~h}$ (entry 1 ), due to the low reactivity of anhydride 7 with electron-donating $\mathrm{OBn}$ and OMOM groups. The use of $\mathrm{CHCl}_{3} /$ collidine (9/1) instead of $\mathrm{CHCl}_{3}$ as a solvent gave much better results. 1,4-Digallate 9 was obtained as the major product in $54 \%$ yield when the reaction was performed at $20^{\circ} \mathrm{C}$ (entry 2). The corresponding reaction at -40 ${ }^{\circ} \mathrm{C}$ gave 9 in $83 \%$ yield with much improved regioselectivity (entry 3). The observed strong temperature-dependence of the regioselectivity indicates that the $\Delta \mathrm{S}^{\ddagger}$ term significantly contributes to the regioselective reaction, suggesting that hydrogen-bonding interaction between the catalyst and the substrate may be responsible for the high regioselectivity, as previously proposed for the regioselective acylation of

Table 1. Optimization of organocatalytic regioselective acylation of 6 .

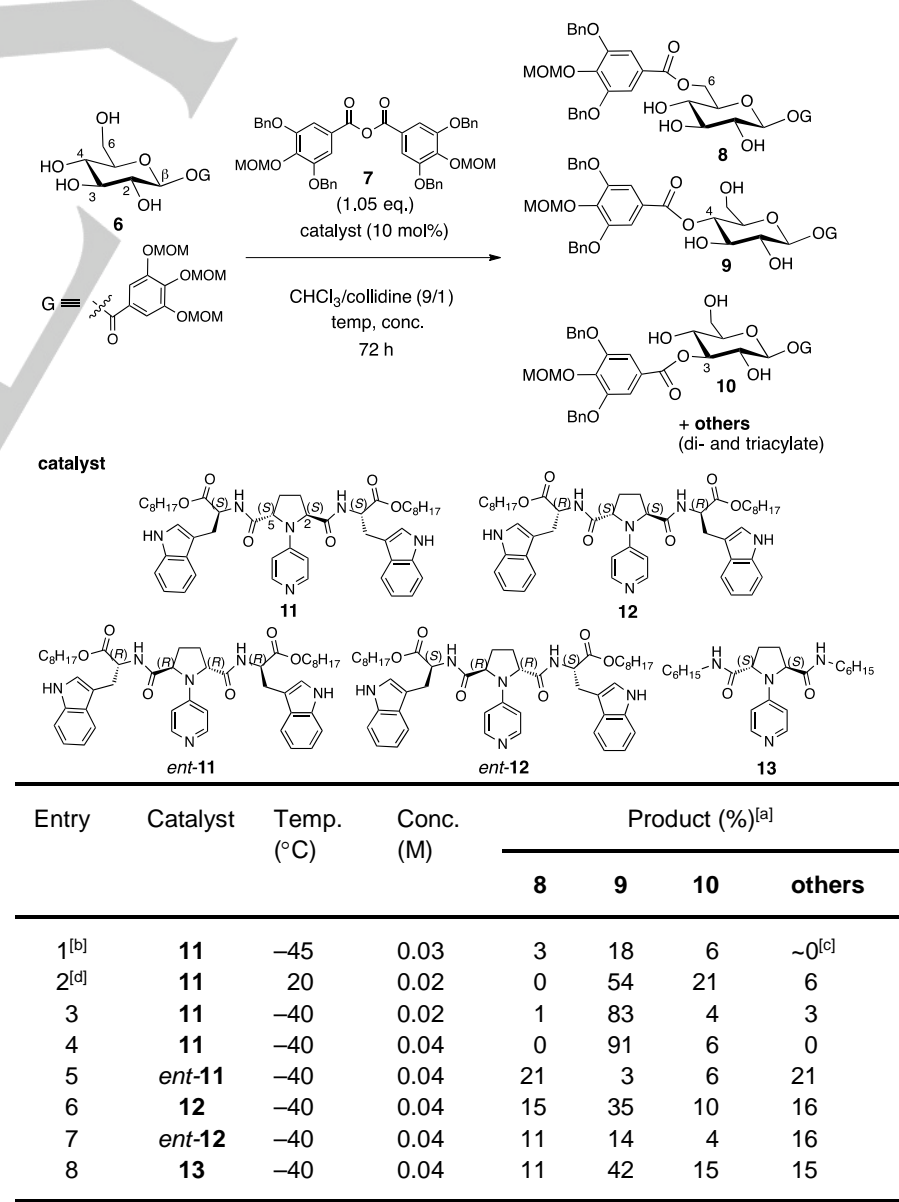

[a] Yields were determined by ${ }^{1} \mathrm{H}$ NMR with 1,3-dinitrobenzene as an internal 
standard. [b] Run in $\mathrm{CHCl}_{3}$ in the presence of 1.5 eq. of 2,4,6-collidine. [c] $70 \%$ of SM was recovered. [d] Run for $24 \mathrm{~h}$.

carbohydrates. ${ }^{[18,20,21]}$ The best result was obtained in the reaction at a substrate concentration of $0.04 \mathrm{M}$, which gave 9 in $91 \%$ yield (entry 4). Use of catalysts ent-11 and ent-12 with the $(2 R, 5 R)$-pyrrolidine skeleton resulted in regio-random reactions (entries 5 and 7). On the other hand, catalyst 12 and 13 with the (2S,5S)-pyrrolidine skeleton same as catalyst $\mathbf{1 1}$ gave $\mathbf{9}$ as the major regioisomer in moderate yields (entries 6 and 8). These results indicate that the stereochemistry of the pyrrolidine skeleton of the catalysts has the major effects on the regiochemistry of acylation, while the structure and stereochemistry of the amide side chains has only minor effects. Thus, catalyst $\mathbf{1 1}$ was found to enable the conventionally difficult molecular transformation with a significant reversal of the innate reactivity of the substrate via fine molecular recognition of the substrate structure.
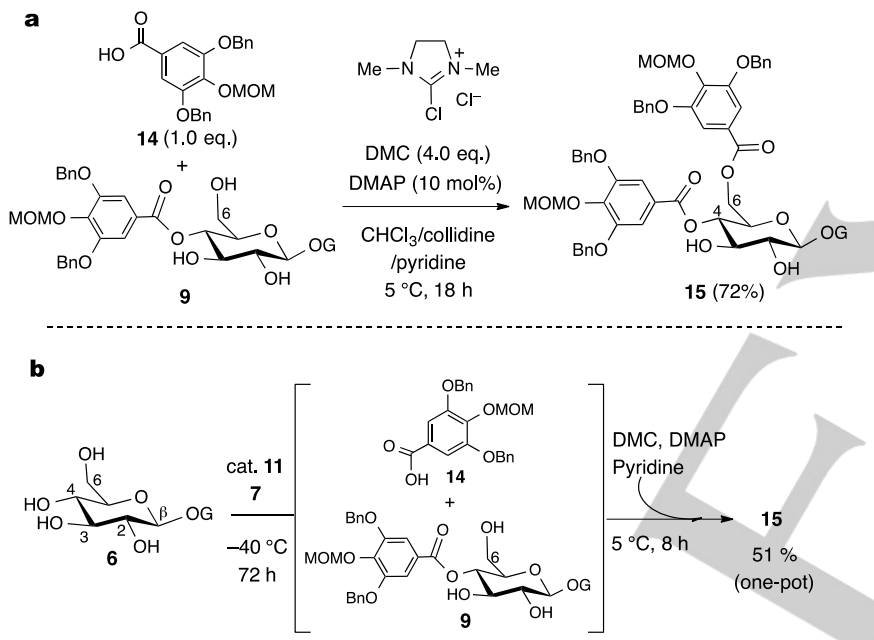

Scheme 3. a) Substrate-controlled regioselective acylation of $\mathrm{C}(6)-\mathrm{OH}$ in $\mathbf{9}$. b) One-pot regioselective diacylation of 6 via catalyst-controlled regioselective C(4)-O-galloylation followed by substrate-controlled C(6)-O-galloylation.
We next examined introduction of a galloyl group to the primary $\mathrm{C}(6)-\mathrm{OH}$, which seems to be the most reactive hydroxy group among three free hydroxy groups of glycoside $\mathbf{9}$ (Scheme 3a). The regioselective introduction of a galloyl group to the $\mathrm{C}(6)-\mathrm{OH}$ of 9 was readily accomplished by treatment with gallic acid derivative 14 and 2-chloro-1,3-dimethylimidazolinium chloride (DMC) to give 15 in $72 \%$ yield. Since 14 was expected to be generated in situ from anhydride 7 and catalyst 11, a onepot procedure for the sequential introduction of two galloyl groups at $\mathrm{C}(4)-\mathrm{OH}$ and $\mathrm{C}(6)-\mathrm{OH}$ of 6 was examined (Scheme

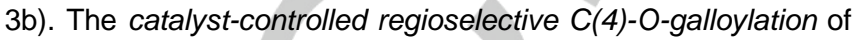
6 with 7 in the presence of catalyst $\mathbf{1 1}$ followed by substratecontrolled C(6)-O-galloylation with in situ-generated 14 took place successfully to give $\mathbf{1 5}$ in 51\% isolated yield in one pot (53 $\mathrm{mg}$ of 15 from $40 \mathrm{mg}$ of 6 ). This key transformation could be scalable to give $1.07 \mathrm{~g}$ of $\mathbf{1 5}$ in $50 \%$ yield from $\mathbf{6}$ with sufficient reproducibility.

Conversion of $\mathbf{1 5}$ into strictinin (1) was shown in Scheme 4. Removal of the benzyl groups of 15 by hydrogenation proceeded smoothly to give $\mathbf{1 6}$ in $98 \%$ yield. The oxidative phenol coupling of the resulting phenol derivative 16 was accomplished according to the method developed by Yamada and co-workers. ${ }^{[13]}$ By treatment of 16 with $\mathrm{CuCl}_{2} / n-\mathrm{BuNH}_{2}$, intramolecular oxidative phenol coupling between the 4- and 6gallate took place to give the corresponding HHDP derivative $\mathbf{1 7}$ with complete control of the newly formed chiral axis $(S)$ in the HHDP moiety. Removal of the MOM groups of $\mathbf{1 7}$ realized the total synthesis of strictinin (1) in five overall steps and $21 \%$ overall yield from naturally abundant glucose. The overall number of the steps in the present synthesis is much less than those previously reported (11 and 13 steps from glucose, respectively ${ }^{[12,13]}$.

We next examined the total synthesis of tellimagrandin II (2) using the present strategy (Scheme $4 \mathrm{~d}$ )-f)). Introduction of two additional galloyl groups at $\mathrm{C}(2)-\mathrm{OH}$ and $\mathrm{C}(3)-\mathrm{OH}$ of diol 15 by the reaction with 5 in the presence of $\mathrm{EDCl} \bullet \mathrm{HCl}$, followed by hydrogenolysis of the resulting 1,2,3,4,6-pentagallate gave $\mathbf{1 8}$. Pentagallate 18 was transformed into tellimagrandin II by the

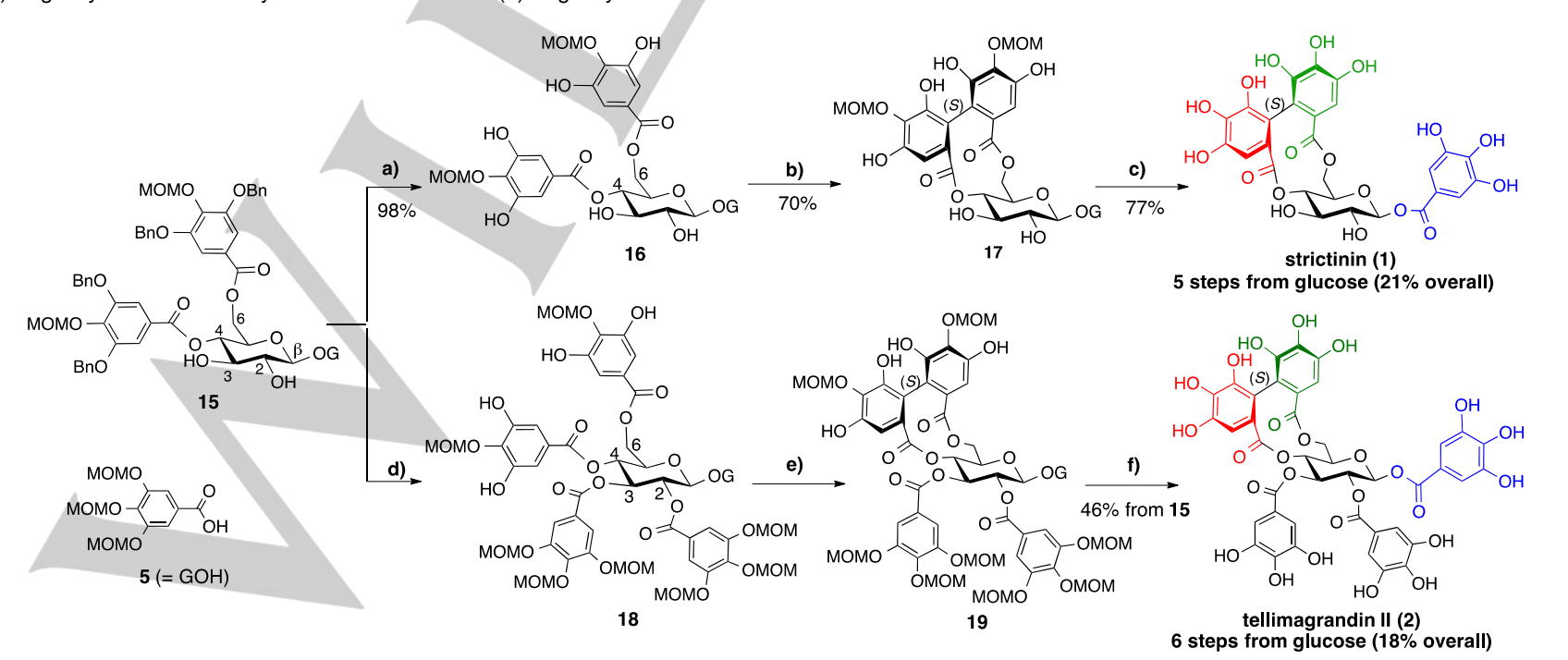


Scheme 4. Total syntheses of strictinin (1) and tellimagrandin II (2). Reagents and conditions: a) $\left.\mathrm{H}_{2}, \mathrm{Pd}(\mathrm{OH}) 2 / \mathrm{C}, \mathrm{THF}, \mathrm{rt} ; \mathrm{b}\right) \mathrm{CuCl} 2, n$ - $\mathrm{BuNH} 2, \mathrm{MeOH}_{2} \mathrm{CHCl} 3(1 / 1)$, rt; c) conc. $\mathrm{HCl} / \mathrm{i}-\mathrm{PrOH} / \mathrm{THF}(1 / 50 / 50)$, rt; d) 5, EDCl•HCl, DMAP, $\mathrm{CH}_{2} \mathrm{Cl}_{2}$, rt then $\mathrm{H}_{2}, \mathrm{Pd}(\mathrm{OH})_{2} / \mathrm{C}$, THF, rt; e) same as b); f) same as c)

same procedure as used for the transformation of 16 to strictinin. Tellimagrandin II (eugeniin) was synthesized from glucose in six overall steps and in $18 \%$ overall yield. The number of synthetic steps from glucose is much less than that of previous total synthesis of tellimagrandin II (14 steps $\left.{ }^{[22]}\right)$.

Since carbohydrate synthesis has been developed in parallel with the development of protective groups, the current carbohydrate synthesis still relies largely on the protectivegroup strategy. ${ }^{[23]}$ On the other hand, approaches to the direct regioselective manipulation of carbohydrates have been reported, recently. ${ }^{[24-26]}$ We developed a de novo synthetic route to natural glycosides of an ellagitannin family via the sequential and regioselective introduction of galloyl(oxy) groups to unprotected glucose. The present strategy would provide a new retrosynthetic approach to a limited class of natural glycoside. We expect that the concept for the catalystcontrolled regioselective functionalization ${ }^{[27]}$ will stimulate further developments in the direct methods for the synthesis of complex natural products with minimum use of the protective groups.

Keywords: organocatalyst • regioselectivity $\bullet$ glycosidation • total synthesis • ellagitannin

[1] S. Quideau, K. S. Feldman, Chem. Rev. 1996, 96, 475-503.

[2] S. Quideau, D. Deffieux, C. Douat-Casassus, L. Pouységu, Angew. Chem. Int. Ed. 2011, 50, 586-621.

[3] L. Pouységu, D. Deffieux, G. Malik, A. Natangelo, S. Quideau, Nat. Prod. Rep. 2011, 28, 853-874.

[4] For the recent studies for total synthesis of ellagitannnins, see: a) Y. Kasai, N. Michihata, H. Nishimura, T. Hirokane, H. Yamada, Angew. Chem. Int. Ed. 2012, 51, 8026-8029. b) H. Yamada, K. Ohara, T. Ogura, Eur. J. Org. Chem. 2013, 35, 7872-7875. c) T. Hirokane, Y. Hirata, Y. Ishimoto, K. Nishii, H. Yamada, Nat. Commun. 2014, 5, 3478-3487.

[5] K. Freudenberg, Chem. Ber. 1919, 52, 1238-1246

[6] T. Okuda, T. Yoshida, M. Ashida, H. Yazaki, J. Chem. Soc. Perkin. Trans. I 1983, 1765-1772.

[7] C. K. Wilkins, B. A. Bohm, Phytochemistry, 1976, 15, 211-214.

[8] M. Kurokawa, T. Hozumi, M. Tsurita, S. Kadota, T. Namba, K. Shiraki, J. Pharmacol. Exp. Ther. 2001, 297, 372-379.
[9] Y. Kashiwada, G. Nonaka, I. Nishioka, K. J.-H. Lee, I. Bori, Y. Fukushima, K. F. Bastow, K.-H. Lee, J. Pharm. Sci. 1993, 82, 487492.

[10] R. K. Saha, T. Takahashi, Y. Kurebayashi, K. Fukushima, A. Minami N. Kinbara, M. Ishitani, Y. M. Sagesaka, T. Suzuki, Antiviral. Res. 2010, 88, 10-18.

[11] H. Tachibana, T. Kubo, T. Miyase, S. Tanino, M. Yoshimoto, M. Sano, M. Yamamoto-Maeda, K. Yamada. Biochem. Biophys. Res. Commun. 2001, 280, 53-60.

[12] K. Khanbabaee, C. Schulz, K. Lötzerich, Tetrahedron Lett. 1997, 38, 1367-1368.

[13] N. Michihata, Y. Kaneko, Y. Kasai, K. Tanigawa, T. Hirokane, S Higasa, H. Yamada, J. Org. Chem. 2013, 78, 4319-4328.

[14] Examples for selective introduction of acyl groups at $\mathrm{C}(3)-\mathrm{OH}$ into 6-Oprotected glucopyranosides were reported. See: a) N. Moitessier, P. Englebiennea, Y. Chapleur, Tetrahedron, 2005, 61, 6839-6853. b) W Muramatsu, T. Kawabata, Tetrahedron Lett. 2007, 48, 5031-5033.

[15] A. V. Demchenko, Ed: Handbook of Chemical Glycosylation: Advances in Stereochemistry and Therapeutic Relevance, Wiley- $\mathrm{VCH}$ Verlag GmbH \& Co. KgaA, Weinheim (2008)

[16] A. Kobayashi, S. Shoda, S. Takahashi, Process for producing glycoside derivative. International Patent WO 2006038440 A1, 2006.

[17] F. Reineri, D. Santelia, A. Viale, E. Cerutti, L. Poggi, T. Tichy, S. S. D. Premkumar, R. Gobetto, S. Aime, J. Am. Chem. Soc. 2010, 132 7186-7193.

[18] T. Kawabata, W. Muramatsu, T. Nishio, T. Shibata, H. Schedel, J. Am Chem. Soc. 2007, 129, 12890-12895.

[19] For the pioneering studies for regioselecive acylation of carbohydrates, see: a) T. Kurahashi, T. Mizutani, J. Yoshida, J. Chem. Soc. Perkin Trans. 1, 1999, 465-473. b) K. S. Griswold, S. J. Miller, Tetrahedron, 2003, 59, 8869-8875

[20] Y. Ueda, W. Muramatsu, K. Mishiro, T. Furuta, T. Kawabata, J. Org. Chem. 2009, 74, 8802-8805.

[21] Y. Ueda, K. Mishiro, K. Yoshida, T. Furuta, T. Kawabata, T. J. Org. Chem. 2012, 77, 7850-7857.

[22] K. S. Feldman, K. Sahasrabudhe, J. Org. Chem. 1999, 64, 209-216.

[23] C.-C. Wang, J.-C. Lee, S.-Y. Luo, S. S. Kulkarni, Y.-W. Huang, C.-C. Lee, K.-L. Chang, S.-C. Hung, Nature 2007, 446, 896-899.

[24] D. L. Lee, M. S. Taylor, Synthesis 2012, 44, 3421-3431.

[25] S. Han, S. J. Miller, J. Am. Chem. Soc. 2013, 135, 12414-12421.

[26] X. Sun, H. Lee, S. Lee, K. L. Tan, Nat. Chem. 2013, 5, 790-794.

[27] For the selected studies for the catalyst-controlled regioselective transformations, see: a) P. A. Lichtor, S. J. Miller. Nat. Chem. 2012, 4 990-995. b) T. Höke, E. Herdtweck, T. Bach, Chem. Commun, 2013 49, 8009-8011. c) P. E. Gormisky, M. C. White, J. Am. Chem. Soc 2013, 135, 14052-14055 
Entry for the Table of Contents (Please choose one layout)

\section{COMMUNICATION}

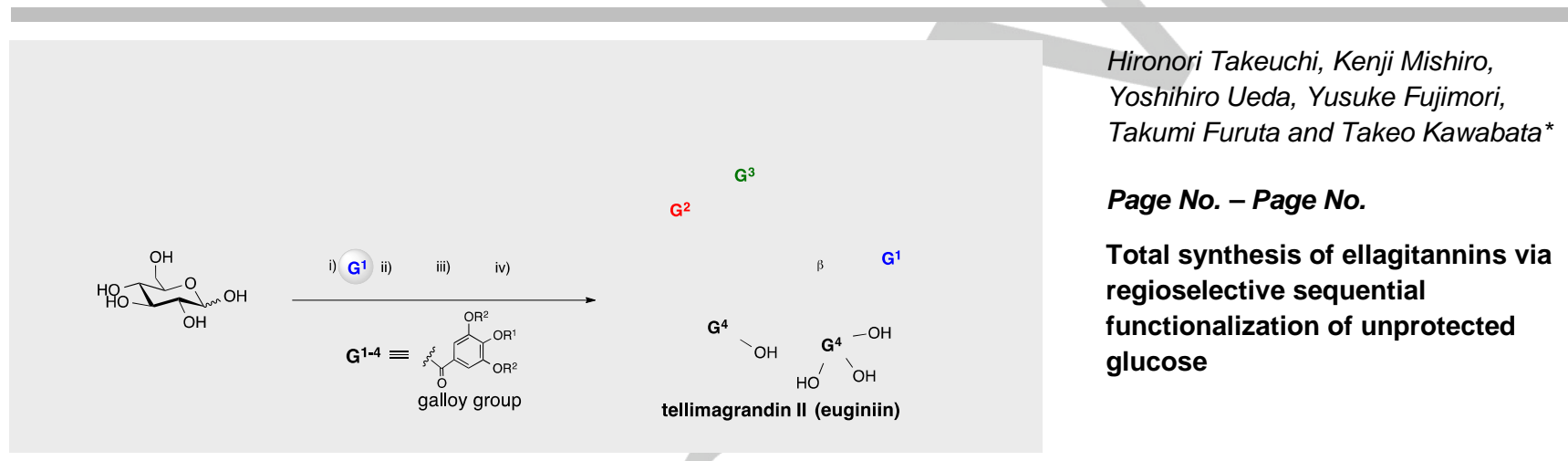

Extremely short-step total syntheses of ellagitannins have been achieved via sequential and regioselective functionalization of hydroxy groups of unprotected glucose.. 